\title{
GESTÃO PARTICIPATIVA: A TRAJETÓRIA NO BRASIL
}

\section{Miguel Luiz Marun Pinto}

\author{
Miriam Brum da Silva Costa
}

\section{RESUMO}

Este artigo apresentará um breve histórico da trajetória da gestão participativa no Brasil, destacará seu mais famoso precursor, bem como empresas que obtiveram sucesso através de sua aplicabilidade. Abordará alguns estilos de administração que visam buscar o desempenho da gestão de pessoas. Mostrará que todos os seres humanos são criativos, decididos, responsáveis e inovadores na vida pessoal, profissional e social; e quando valorizados, contribuem para o crescimento e aprimoramento das organizações. Atualmente as empresas não pensam no funcionário apenas como máquina sem inteligência ou poder de decisão: as organizações vêm investindo na motivação de seus funcionários, tornando-os verdadeiros líderes capazes de persistir em face de frustrações e obstáculos, com a finalidade de descobrir seus melhores talentos e juntos atingir objetivos comuns. Sendo assim, neste mundo globalizado e competitivo, as empresas que não valorizarem seus funcionários - tornando-os integrados ao processo de trabalho, comprometidos e satisfeitos - dificilmente permanecerão no mercado.

Palavras-chave: Gestão participativa. Responsabilidade. Valorização.

\begin{abstract}
This paper presents a reflection about of the trajectory of the shared management in Brazil, will point the most famous pioneer. And the companies that found success across his applicability. We focused some style of administration that take as a target to obtain the managerial styles of human resource management. We discuss that human are creative, determined, responsible and innovative in the personal, professional and social life. The human beings when they are valued, contributing to the growth and the progress of the organizations. At present the companies do not see the worker as a machine without intelligence or decision power. The companies that invest in the motivation of his employees so that are real leaders able of facing the obstacles and it continues of frustrations, were transforming in talented leaders. However, in this globalized and competitive world, the companies that do not value his employees, making them integrated to the process of work, what they compromised and satisfied, probably they will not remain on the business market.
\end{abstract}

Keywords: Shared management. Social responsibility. Human resource. 


\section{INTRODUÇÃo}

0 presente artigo enfocará a importância de trabalhar a gestão participativa nas organizações. Abordará brevemente seu surgimento no Brasil através do histórico de seu mais famoso precursor, Irineu Evangelista de Souza, o Barão de Mauá. Embora vivesse em uma sociedade escravocrata, o Barão foi destemido ao contratar empregados como mão-de-obra remunerada, além de inovador e revolucionário, implantando a gestão participativa. Destacará, ainda, alguns estilos de administração, tais como: Teoria X e Y, os Sistemas Administrativos, o Círculo de Controle da Qualidade - CCQ's. Mostrará como a Associação Nacional de Administração Participativa - ANPAR se tornou um grande instrumento para a troca de experiências entre as empresas, no que tange à participação responsável dos funcionários nas decisões, bem como nos lucros da empresa. E como duas grandes empresas obtiveram sucesso com a implantação da gestão participativa.

0 que justifica este artigo é a importância que a gestão participativa tem demonstrado para o crescimento e sucesso das organizações e mostrando de que forma ela vem contribuindo para um melhor desempenho dos dirigentes na gestão de pessoas, considerando, de forma geral, que quando os funcionários são valorizados, eles sentem-se impelidos a colaborar para que a empresa atinja seus objetivos. Sendo assim, neste mundo globalizado e competitivo, as empresas que não valorizam seus funcionários, não os integram no processo de trabalho, não permite que se sintam motivados, satisfeitos, envolvidos e comprometidos com o trabalho, dificilmente se mantêm no mercado.

Nesse sentido, objetivo desse trabalho é apresentar a trajetória da gestão participativa no Brasil, demonstrando como sua aplicabilidade tem contribuído para o crescimento das organizações.

\section{HISTÓRICO DA GESTÃO PARTICIPATIVA}

Assim como as leis antes de serem regulamentadas surgem de costumes adotados pelo povo (como, por exemplo: na antiguidade, o direito a propriedade; e a lei do divórcio mais recentemente), também a gestão participativa no Brasil surgiu de uma revolução silenciosa em organizações onde funcionários passaram a participar da administração e dos lucros.

Podemos citar como um de seus precursores mais famosos alguém que desde cedo aprendeu a lidar com planejamento, análises econômicas e informações de mercado, e que em diversas situações foi capaz de analisar o cenário para tomada de decisão. Não tinha medo do novo e ultrapassou sua existência, simplesmente pela menção de seu nome. Estamos falando do grande empresário Irineu Evangelista de Souza, mais conhecido como Barão de Mauá ou Visconde de Mauá.

Nascido no município de Arroio Grande, distrito de Jaguarão, Estado do Rio Grande do Sul, no dia 28 de dezembro de 1813, tornou-se um grande industrial, banqueiro, político e diplomata, - que foi e é considerado a maior figura do segundo Império - possuía uma essência progressista e emancipadora. Primeiro representante legítimo da burguesia brasileira, viu com enorme clareza a potencialidade do Brasil como país, como nacionalidade. Mauá teve destaque nos serviços públicos, através da organização de companhias de navegação a vapor no Rio Grande do Sul e no Amazonas. Em 1852 implantou a primeira ferrovia brasileira ligando Petrópolis e Rio de Janeiro e, em 1854 implantou a Companhia de Gás para a iluminação pública do Rio de Janeiro e dois anos depois inaugurou o trecho inicial da primeira rodovia pavimentada do país, a União e Indústria, entre Petrópolis e Juiz de Fora. Criador de 
mudanças, num meio em que os grandes empresários privados possuíam apenas uma empresa, Mauá apostou na diversificação e montou várias indústrias - mesmo vivendo em um país onde a cultura predominante era a da agricultura. Foi um revolucionário ao contratar empregados como mão-de-obra e não escravos, base do sistema produtivo na época: foi então que implantou a gestão participativa.

Implantou em seus empreendimentos um modelo inovador e característico de gestão de pessoas. Segundo Fontes Filho em seu artigo "O empreendedorismo no sistema cultural brasileiro: a história do Barão de Mauá" ${ }^{1}$, tratava-se de um sistema de gerência altamente descentralizada, o que valorizava a responsabilidade individual do empregado e o trabalho que desenvolvia.

Também investia em salários mais altos com o propósito de ter o melhor pessoal a seu lado. 0 artigo ainda mostra que Mauá condenava o nepotismo, mas valorizava a meritocracia, ou seja, o merecimento próprio. Mas apesar de suas práticas participativas, Mauá mantinha sob sigilo e controle centralizado suas contas e as de suas empresas: Graças a seu método de controle solitário, só ele mesmo sabia o valor total do conjunto de suas empresas. 0 balanço consolidado do império existia apenas em sua cabeça, e ele gabava de reter na memória os valores do caixa de cada empreendimento" (apud Caldeira; Fontes Filho, 2008, p. 14).

No Brasil, tudo o que significasse desenvolvimento e progresso e que não fosse à custa do trabalho escravo tinha a marca de Mauá. O Barão controlou oito das dez maiores empresas do país: as exceções eram o Banco do Brasil e a Estrada de Ferro D.Pedro II, ambas estatais. Por volta de 1867, possuía uma fortuna no valor de 115 mil contos de réis, enquanto o orçamento do Império era de 97 mil contos de réis, o que hoje equivaleria a 60 milhões de dólares.

Mauá era um incompreendido, um "estranho no ninho", pois vivia num país que na época era ruralista, escravocrata e latifundiário ${ }^{2}$, cuja economia era controlada pelo Estado. Ao longo de sua vida, Irineu Evangelista de Souza recebeu dois títulos: em 1854, o de Barão de Mauá, e, em 1874, o de Visconde de Mauá. Ele morreu em Petrópolis no dia 21 de outubro de 1889 devido ao diabetes. Embora falido, pagou todas as suas dívidas, morreu famoso e respeitado na Europa, considerado como um dos impulsionadores do progresso material no Segundo Reinado.

\section{ESTILOS DE ADMINISTRAÇÃO}

\section{As teorias $\mathrm{X}$ e $\mathrm{Y}$}

$\mathrm{Na}$ administração das empresas existem fortes estilos de direcionamento no comportamento das pessoas por parte dos administradores. Estilos que não só dependem das convicções que os administradores têm com respeito ao comportamento humano, mas também na maneira como direcionam e conduzem as pessoas. A este respeito podemos citar as duas teorias de McGregor: a Teoria X (ou tradicional) e a Teoria Y (ou moderna), ambas baseadas em concepções antagônicas sobre como administrar. De um lado temos a Teoria X, com estilo definido pela Administração Científica de Taylor ${ }^{3}$, pela Teoria Clássica de Fayol$^{4}$ e pela Teoria da Burocracia de Werber ${ }^{5}$, com características tradicionais, mecanicistas, pragmáticas e distorcidas em relação à natureza humana, com um estilo de administrar duro, rígido e autocrático, no qual as pessoas trabalham da maneira como a organização pretende que trabalhem: um estilo que inibe a criatividade e a iniciativa individuais, pressupondo que elas são indolentes, preguiçosas, que evitam o trabalho, pessoas que precisam ser controladas e dirigidas, ou seja, meros recursos ou meios de produção. 
${ }^{1}$ FILHO, Joaquim Rubens Fontes. 0 empreendedorismo no sistema cultural brasileiro: a história do Barão de Mauá

2 Possui uma grande extensão de terra improdutiva

3 A Administração Científica de Taylor, que abordava tanto técnicas de controle e de produção quanto uma visão unificada da administração, provou que a maioria dos trabalhos especializados poderiam ser divididos em passos a serem executados por trabalhadores não-especializados.

4 Segundo Fayol, administrar é planejar, organizar, executar, liderar e controlar. Para ele, toda empresa - de qualquer ramo ou atividade - apresenta seis tipos de atividade: produção, comércio, finanças, segurança, contabilidade e administração.

5 Uma mudança da organização baseada em valores e ações — autoridade tradicional — para a organização orientada para objetivos e ações - legal e racional, que possuíam três características principais: formalidade, impessoalidade e profissionalismo.

Do outro lado, temos a Teoria Y, baseada num estilo moderno, apregoado pela Teoria Comportamental ${ }^{6}$, aberto, democrático, dinâmico e participativo, baseado nos valores humanos e sociais. Encoraja o crescimento individual, cuja forma de administrar torna-se um processo de criar oportunidades e estilos administrativos, e traz pressupostos positivos — ou seja, os de que as pessoas são esforçadas, gostam de ter o que fazer, aceitam responsabilidades, desafios, são criativas e competentes. Podemos dizer que a Teoria Y adota uma série de medidas inovadoras e humanistas, tais como a descentralização das decisões e a participação, a delegação de responsabilidades e a administração consultiva, o que proporciona aos funcionários dirigirem suas atividades, assumirem os desafios decorrentes de tais decisões e ao mesmo tempo alcançarem a autorealização.

\section{Sistemas administrativos}

Na década de 1960, com o objetivo de comparar os modelos tradicional e participativo de organização, o americano Rensis Likert procurou em suas pesquisas as características das organizações de melhor e pior desempenho.

Segundo Chiavenato (2000, p. 290-292)7, a ação administrativa assume feições diferentes dependendo das condições internas da empresa. E nunca é igual em toda empresa: existem inúmeras variáveis, que dependem de fatores internos e externos. Nesse sentido, Likert, considerado o expoente da Teoria Comportamental, apontou quatro sistemas administrativos, a saber: sistema 1 - autoritário coercitivo; sistema 2 - autoritário benevolente; sistema 3 consultivo; e sistema 4 - participativo. No entanto, Likert concluiu que as organizações identificadas com o sistema 4 tinham melhor desempenho, mediu a satisfação de seus funcionários e seus resultados econômico-financeiros.

\section{Círculos de controle de qualidade - CCQ'S}

Com o desenvolvimento do fenômeno da globalização da economia, as organizações vêm se deparando com vários desafios. Entre eles, podemos citar o código do consumidor e a crescente exigência dos consumidores, que, aliados aos novos padrões de qualidade e produtividade no mercado altamente competitivo, têm obrigado as organizaçõ es a buscar novas soluções. Desta forma, surge o movimento dos Círculos de Controle de Qualidade CCQs, criado pelo Professor Kaoru Ishikawa no Japão por volta 1962, como resultado dos padrões de qualidade das indústrias japonesas e os conseqüentes contatos entre as 
universidades e os operários de fábrica.

No Brasil, este movimento surge por volta de 1972 nos setores de qualidade e produção da Johnson \& Johnson, em conseqüência da identificação da necessidade de um programa motivacional de apoio à qualidade, após o surgimento de todos os tipos de problemas com seus funcionários. Podemos defini-lo como um pequeno grupo de funcionários voluntários que pertencem ou não à mesma área de trabalho, com o mesmo treinamento, conhecimento e objetivos, que buscam melhorar seu desempenho, reduzir os custos, aumentar a eficiência, principalmente no que se refere à qualidade dos seus produtos ou de seu trabalho.

Os CCQs buscam aumentar a motivação dos funcionários, fazendo com que se sintam autorealizados através da oportunidade de participação na solução dos problemas da empresa, do incentivo à formação de uma mentalidade de qualidade disseminando a filosofia do autocontrole e da prevenção das falhas. Os CCQs também buscam a garantia da qualidade dos produtos, novas idéias, aumento na produtividade do trabalho, redução nos custos e diminuição das perdas, como também a melhora na comunicação e no relacionamento interpessoal, tanto no sentido horizontal como vertical. Eles podem solucionar também problemas ligados às condições de trabalho e ao ambiente físico, tais como: iluminação, ventilação, limpeza, ruído e problemas na área administrativa.

6 Também conhecida como Escola Behaviorista (do inglês: behavior = comportamento), a Teoria Comportamental surgiu como produto da simbiose, ou seja, da reunião de duas das idéias centrais de dois movimentos anteriores (Administração Científica e Relações Humanas).7 CHIAVENATO, Idalberto. Administração: teoria, processo e prática. 3. ed. São Paulo: Makron Boocks, 2000

\section{ESTRUTURAÇÃO DA GESTÃO PARTICIPATIVA}

\section{Associação nacional de administração participativa - ANPAR}

No que se refere ao desafio enfrentado com sucesso por muitas empresas brasileiras há sempre um elemento comum: a gestão participativa. Podemos citar um grande instrumento deste projeto: a ANPAR - Associação Nacional de Administração Participativa, entidade sem fins lucrativos, constituída em 1985, em São Paulo, e dois dos seus grandes membros. Um deles é Plínio Assmann, Presidente da ANPAR, que foi Secretário do Transporte do governo Mário Covas. Plínio modernizou a gestão das empresas públicas, foi o primeiro presidente do Metrô de São Paulo, instituição que conseguiu despertar a admiração dos paulistanos por ter qualidade no serviço que presta, e conseguiu até mesmo que uma estatal paulista, a COSIPA Companhia Siderúrgica Paulista gerasse lucro. O outro membro é Francisco de Paula Lima, Vice-presidente da ANPAR, que merece destaque por sua participação alavancadora na luta pela implantação da gestão participativa — ele foi o maior entusiasta desta entidade.

A Associação Nacional de Administração Participativa - ANPAR tem como missão contribuir para o desenvolvimento e a pesquisa junto a empresas associadas da ANPAR e da ABINEE Associação Brasileira da Indústria Elétrico Eletrônica, que somam um total de 97 empresas associadas, sendo que, 60 delas implantaram alguma modalidade de administração participativa (MATSUBARA, 1995, P. 1)

A ANPAR foi criada com o objetivo de oferecer condições para que as organizações, bem como as pessoas e comunidades pudessem realizar trocas quanto a suas experiências de administração nas quais prevalecessem as participações responsáveis e o respeito aos interesses e à realidade cultural de todos os seus participantes. 
A ANPAR realizou muitas conquistas. Dentre elas, podemos citar a criação em 13/05/1993 do Movimento Nacional pela Participação nos Lucros - "Participa Brasil". Segundo foi informado por Fernando Reis, seu Coordenador na época, independentemente de classe social, cor, religião ou ocupação, o movimento em favor da participação dos trabalhadores nos lucros das empresas, era um movimento de sociedade civil, ou um movimento feito por cada cidadão brasileiro.

No final do governo Itamar Franco, como última medida provisória, foi assinada e sancionada a Lei № 4.580 de 1990 que regulamentava a participação dos funcionários nos lucros, o que possibilitou maior eficiência nas empresas.

E partindo do processo de gestão participativa será possível chegar à conscientização da verdadeira cidadania e à conquista de uma qualidade de vida compatível com os padrões do Primeiro Mundo. A meta da ANPAR para os dias de hoje é trazer para o Brasil uma postura administrativa que deverá comandar o próximo milênio.

${ }^{8}$ MATSUBARA, Clarice Mieko. Painel: Participação dos empregados nos lucros das empresas. Disponível em: <www.pr.gov.brbatebyte/edições/1995/bb47/comdex.htm> Acesso em: 30/08/2008

\section{EMPRESAS QUE OBTIVERAM SUCESSO ATRAVÉS DA GESTÃO PARTICIPATIVA}

\section{MÉTODO ENGENHARIA}

A Método Engenharia, situada em São Paulo, no Bairro do Brooklin Novo, atuante no setor da construção civil, em 1992 recebeu da revista Exame o título de "empresa do ano"; em 2000, foi premiada pela mesma revista como uma dentre "as 100 melhores empresas para se trabalhar".

A Método Engenharia acredita e coloca em prática a gestão baseada na participação, embora esta forma de administrar ainda não seja vista com bons olhos no Brasil por algumas empresas. Segundo Hugo Marques Rosa, a Método trabalha a gestão de Recursos Humanos de forma a que as pessoas sejam diretamente responsáveis pelo seu próprio sucesso, ou seja: cada trabalhador é personagem de sua própria história. A empresa foi fundada em São Paulo numa época de ditadura militar em que o setor de construção civil era moldado em um ambiente fechado e conservador. Sem contar que naquele momento havia uma concorrência desleal de outros empresários, com práticas de sonegação de impostos e preços menores por falta de regras e fiscalização.

Além disso, os funcionários reconheciam a existência de uma estrutura fortemente hierarquizada, onde não havia o mínimo de respeito pelo funcionário, uma das características mais fortes das empresas do setor de construção civil. Segundo Betania Tanure (1996, p. $109)^{9}$, os funcionários eram tratados como "troço descartável, o peão era considerado igual ao] filho de um cão vadio". Existia também um grande desperdício de tempo, materiais, tudo era feito de improviso.

\section{Necessidade de mudanças}

Entre os anos de 1981 a 1983 ocorre uma crise muito significativa na economia brasileira, com as transições políticas. Isto mudaria os negócios de muitas empresas, inclusive da Método 
Engenharia, que, surpreendida pela crise, foi forçada a reduzir dois terços de seu quadro de mão-de-obra direta e indireta; conseqüentemente, seu faturamento caiu de US\$ 4 milhões ao mês para US\$ 800 mil ao mês num prazo de seis meses. Em meio a tantas mudanças e dificuldades, e querendo manter os negócios dentro de uma visão diferente, os acionistas viram a necessidade de mudar e seguir as novas tendências. Entenderam que a Método Engenharia necessitava de maior agilidade e flexibilidade para acompanhar as mudanças aceleradas e que, para isso, deveriam buscar mais produtividade, tornar-se um diferencial através da qualidade em sua atuação.

E o objetivo era atender as necessidades dos clientes e manter a dignidade e a qualidade de vida de seus funcionários, pois somente desta forma conseguiriam garantir de forma sustentável a satisfação do cliente e conquistar um poder competitivo que os remunerassem satisfatoriamente. Desta forma, delinearam a estratégia do negócio e da gestão. Um fator primordial naquele momento era a vontade política dos acionistas, que estavam dispostos a mudar a forma de desempenhar o poder e dar maior transparência às decisões tomadas, por criar uma credibilidade junto aos funcionários.

${ }^{9}$ BARROS, Betânia Tanurede; PRATES, Marco Aurélio Spyer. Estilo brasileiro de administrar. 1. ed. São Paulo: Atlas, 1996.

\section{Processo de mudança}

Em 1987 foram formalizados e divulgados amplamente a todos os empregados os documentos Filosofia e Princípios e Políticas, considerados o marco inicial em todo o processo de mudança, pois norteariam a ação dos funcionários no trabalho. Nestes documentos, seus acionistas demonstravam sua vontade irrevogável e a proposta de uma nova forma de condução dos negócios.

Os documentos apresentavam quatro linhas básicas: fazer bem feito - mais do que fazer bem feito para o cliente, a obra deveria seguir um padrão de qualidade diferenciado em relação a todas as outras oferecidas no mercado, considerando a comunidade, seu consumidor final; $a$ empresa como veículo social - a empresa deveria ser não só um instrumento para gerar lucro, mas um instrumento que possibilitasse a seu principal suporte, os seres humanos, o desenvolvimento em suas condições de trabalho, a realização profissional e até mesmo na vida; negociação de troca - cabia à empresa ter um papel claro, e, não, ser apenas uma distribuidora de benefícios de forma paternalista e indiscriminada, mas uma empresa que atendesse as reivindicações justas e que estivesse de acordo com o aprimoramento de seu desempenho; que proporcionasse um ambiente liberal, onde houvesse diálogo, troca e, conseqüentemente, que fosse uma empresa de qualidade; competência garantia de qualidade - a empresa deveria estar atenta ao que ocorresse tanto no ambiente interno quanto no externo, tais como mudanças socioeconômicas e novas tecnologias, e deveria sempre inovar e desenvolver uma liderança que valorizasse os seus funcionários e a organização de seus departamentos.

A Método acreditava e acredita que a remuneração de seus funcionários é uma forma de recompensa e reconhecimento do trabalho; no entanto, defendia a existência de outras formas de desenvolvimento de seus funcionários, entre elas o ambiente empreendedor e a oportunidade de crescimento profissional, social e econômico, a recompensa em grupo como fator importante no estímulo ao bom relacionamento entre as pessoas. A participação dos funcionários foi tão ativa que eles iniciaram em outras empresas - em áreas de atuação 
equivalentes as suas na Método - uma pesquisa salarial em que eles próprios eram os pesquisadores. Mas em todos os casos, um princípio era respeitado: as pessoas deveriam participar em todas as decisões que as afetassem diretamente, não atuando apenas como meros expectadores.

\section{Avaliação das mudanças}

Não se pode afirmar que a mudança cultural ocorrida na Método Engenharia tenha atingido $100 \%$ de seus objetivos, mas podemos dizer que atualmente algumas dessas mudanças são qualitativas em relação ao início do projeto e foram implantadas e assimiladas com êxito, como, por exemplo, a que dispunha da empresa como veículo social. É importante frisar que essas mudanças não são apenas o resultando de um liberalismo inconseqüente, paternalista, mas, sim, estão diretamente ligadas a um processo de troca em que a empresa precisa ter seu resultado de produtividade.

Entenderam que novas situações surgiriam decorrentes das mudanças implementadas, por isso pode-se dizer que esse projeto não foi concluído. A empresa não deve perder seu foco principal: o seu mercado, que é muito competitivo e está sempre em constantes mudanças. Sendo assim, é necessário manter sempre uma atuação competitiva, proporcionando a satisfação dos clientes, funcionários, acionistas, fornecedores e de sua comunidade.

\section{SEMCO}

\section{Necessidades de mudanças}

Outra empresa bem-sucedida em seu ramo de negócios, com uma política de administração participativa é a Empresa Semco \& Company, uma empresa familiar localizada em São Paulo. Originalmente, a empresa vivia do mercado naval, vendendo bombas de água e óleo para navios de grande calado. 0 primeiro produto da Semco foi uma centrífuga resultante de

patente do engenheiro Antonio Curt Semler, Presidente da Semco e pai de Ricardo Semler, nascido em São Paulo em 1959, autor do best-seller Virando a própria mesa, livro no qual relata a grande revolução que fez ao assumir o controle da Semco no lugar de seu pai no início da década de 1980 — o que ele não imaginava é que a Semco se tornaria uma das empresas mais conhecidas do mundo.

Em favor da descentralização, de uma gestão participativa, Ricardo Semler entedia que a Semco dependia de inteligências diversificadas, inclusive a emocional, que está relacionada a aspectos tais como autoconsciência, sentimentos, motivação, empatia e relacionamento social, ao contrário de seu pai, que mantinha uma estrutura autocrática tradicional na gestão dos negócios.

Ao assumir a Semco, Ricardo Semler tinha forte desejo de diversificar os negócios. Nos anos de 1980 e 1981, a Semco enfrentou algumas dificuldades devido à crise no ramo naval, e Ricardo foi obrigado a mudar rapidamente ou o trabalho de tantos anos iriam se perder aos poucos. Sendo assim, fez algumas mudanças e uma delas foi à dispensa de vinte e duas das 110 pessoas que trabalhavam na Semco, entre as quais estavam gerentes gerais, financeiros, de produção e de vendas que, segundo SEMLER (1998, p. 330)10, eram homens que impediam a profissionalização da empresa. E, sob oposição de seu pai, iniciou a diversificação dos negócios e o salvamento da empresa. 


\section{Processos de mudanças}

Nos anos seguintes foram muitas as negociações para a incorporação de outras empresas à Semco, e, em 1987, foi realizada a quarta incorporação, a Divisão de equipamentos da Sandvik. Com um total de quatro incorporações de multinacionais, o tamanho da Semco foi multiplicado oito vezes em poucos anos, e o número de funcionários estava quase na casa dos mil.

E após muitas conjecturas Semler chegou à conclusão das condições necessárias para a empresa sobreviver através do tempo. Segundo SEMLER (1998, p. 69)11, essas mudanças seriam ao longo prazo e exigiriam muita perseverança por parte da empresa, são elas: 1) ser capaz de enxergar as necessidades de mudanças e ter coragem de implementá-las em quanto há tempo; 2) conseguir que a empresa funcione com a participação de seus funcionários e ter uma conduta administrativa flexível e aberta às transformações; 3) Ter uma conduta própria e definida, mesmo que não estivesse de acordo com as condições atuais, mas que fosse eterna em suas crenças básicas.

Para Ricardo Semler, o maior obstáculo para implantação da gestão participativa foram os gerentes, pois na maioria das vezes eram mais conservadores com o dinheiro que o próprio acionista. No entanto, era preciso que entendam que eram funcionários e não empresa - pois a empresa é a soma das pessoas.

Outro obstáculo a ser vencido foi à mentalidade de pensar que o lucro da empresa pertencia

somente aos acionistas, ou seja, a quem investia. No entanto, iniciou-se a discussão quanto a se participação nos lucros era viável. Então, em dezembro de 1986, a Semco promoveu o Fórum Nacional de Participação nos Lucros, reunindo quase todas as empresas que praticavam a participação nos lucros num painel de debates e trezentos executivos na platéia. Chegaram à conclusão que ainda teriam muita luta pela frente, visto a participação ainda, na época contar com muitas resistências.

${ }^{10}$ e ${ }^{11}$ SEMLER. Ricardo. Virando a própria mesa. São Paulo: Best Seller, 1998

\section{Avaliação das mudanças}

As portas estavam sempre abertas, sem formalidades, e as pessoas deviam falar o que pensavam sem inibições. Tudo na Semco era e é baseado na confiança. Não existia revista de funcionários na entrada ou na saída; mas, quando ocorria desonestidade, a empresa agia duramente para manter a linha de conduta de todos. Ao completar três anos de casa ou 50 anos de idade, o funcionário só poderia ser demitido após várias aprovações — isto não significa que o funcionário possui estabilidade, mas é uma forma de aumentar a segurança das pessoas.

Segundo SEMLER (1998, p. 266)12, as pessoas só conseguem se realizar onde podem se sentir parte do que acontece a sua volta. Na visão de seus administradores, a longo prazo torna-se impraticável a participação em empresas com muitos funcionários num mesmo lugar. É necessário se dividir. Assim, a Semco está dividida em várias unidades, e sempre que 
uma cresce são criadas subdivisões. 0 objetivo é não trabalhar com mais de duzentas pessoas em cada local e apenas com quatro níveis de divisão.

0 conceito é dar autonomia e liberdade aos gerentes das divisões para que dirijam da melhor forma possível. Sempre que necessário, busquem apoio na corporação central, que é enxuta e ágil e serve também como centro de debates de estratégia e operação. Ricardo Semler acredita que todas essas mudanças foram e são apenas o início e que a empresa precisa melhorar em muito de seus padrões de administração.

\section{CONSIDERAÇõES GERAIS}

A partir do exposto no presente artigo, pode-se considerar que a gestão participativa tem setor nado de suma importância como diferencial para as organizações que a implementaram, tendo em vista que funcionários mais valorizados tornam-se mais produtivos e mais comprometidos com seu trabalho, pois se sentem mais motivados. Todavia, para que esse modelo de gestão obtenha resultados positivos, faz-se necessário estudar e conhecer bem todos os processos envolvidos em sua execução.

É importante ressaltar que a implementação do modelo participativo é um processo demorado, é um trabalho onde estão envolvidas a autonomia, a disciplina, a paixão, a força de vontade, a colaboração e a união de todos. Lembrando que a participação não é somente nas decisões, na participação dos lucros, mas principalmente na responsabilidade por seu próprio comportamento e desempenho.

A meta do modelo participativo é construir uma organização que aprenda a partir dos erros cometidos e dos conflitos existentes, onde as idéias e decisões que afetam as empresas não sejam compartilhadas apenas com os funcionários, mas também com seus clientes, fornecedores e comunidade. Pois, como vimos, na gestão participativa as decisões efetivas precisam ser tomadas pelas pessoas certas, permitindo que estas contribuam com suas experiências, conhecimentos de forma organizada e responsável.

12 SEMLER. Ricardo. Virando a própria mesa. São Paulo: Best Seller, 1998

\section{REFERÊNCIAS BIBLIOGRÁFICAS}

ACHER, Renato. Mauá: empresário e político. Reedição fac-similar da 1. ed. do livro Visconde de Mauá aos credores de Mauá. Banchi, 1987.

AURELlANO, Eliane Bernal; ALBUQUERQUE, Lindolfo Galvão de. Gestão Participativa - um estudo de caso. Out. 1999.

BARROS, Betânia Tanurede; PRATES, Marco Aurélio Spyer. Estilo brasileiro de administrar. 1. ed. São Paulo: Atlas, 1996.

BARSA, Enciclopédia, volume 9, ano 1997. Visconde de Mauá: o maior empresário. São Paulo, jul. 2008. Disponível em: www.nossosaopaulo.com.br. Acesso em: 12/07/2008.

CARVALHO, Antonio Vieira de; SERAFIM, Oziléa Clen Gomes. Administração de recursos humanos. 2. vol. São Paulo: Pioneira, 1995. 
CHIAVENATO, Idalberto. Administração: teoria, processo e prática. 3. ed. São Paulo: Makron Boocks, 2000.

Artigo. Circulo de Controle de Qualidade. Disponível em: <mhtml://c: \Documents and settings> Acesso em: 18/09/2008

DINIZ, Sergio. Gestão participativa. Artigo SEBRAE, São Paulo, jun. 2008. Disponível em: <http://www.scbracsp.com.br/principal/scu/ncg/cio/produto>. Acesso em: 24/06/2008.

FILHO, Joaquim Rubens Fontes. 0 empreendedorismo no sistema cultural brasileiro: a história do barrão de Mauá.

FERREIRA, Ademir Antonio; REIS, Ana C. F. e PEREIRA, Maria I. Gestão empresarial: de Taylor aos nossos Dias. São Paulo: ED. Pioneira, 2002

MANAGER, Online. jul. $2007 . \quad$ Disponível em: www.manager.com.br/reportagem/reportagem.php Acesso em 23/07/2008.

MATSUBARA, Clarice Mieko. Painel: Participação dos empregados nos lucros das empresas. Disponível em: <www.pr.gov.brbatebyte/edições/1995/bb47/comdex.htm> Acesso em: $30 / 08 / 2008$.

MAXIMIANO, Antonio César Amaru. Teoria geral da administração. 1. ed. São Paulo: Atlas, 2008.

MOGGI, Jair. Brasil participativo, uma revolução silenciosa. Agos. 2008. Disponível em: www.adigo.com.br/br/artigos.asp. Acesso em: 20/08/2008.

SQUASSONI, Enéas. Direção do futuro. Associação Nacional de Administração Participativa ANPAR. Documento cedido por Fernando Reis antigo Conselheiro da ANPAR.

PINSKI, Isaac; ROCHA, Donatila Brasil. Gestão Participativa com valorização do trabalhador. Um estudo de caso. Santos - SP

SEMLER. Ricardo. Virando a própria mesa. São Paulo: Best Seller, 1998.

. Você está louco! Uma vida administrada de outra forma. Rio de Janeiro. Rocco,

2006. 